\title{
Physicochemical Characteristics of Two Prototypical Home-Use Consumer Products Containing Engineered Nanomaterials
}

\section{Christie M Sayes $^{1^{*}}$, Aishwarya Sooresh ${ }^{2}$ and Kenith E Meissner ${ }^{2,3}$}

${ }^{1}$ Department of Environmental Science, Baylor University, Waco, Texas, USA

${ }^{2}$ Department of Biomedical Engineering, Texas A \& M University, College Station, Texas, USA

${ }^{3}$ College of Engineering, Swansea University, Singleton Park, Swansea, Wales, UK

\begin{abstract}
The extensive use of nanomaterials in new products for the building envelope is expanding rapidly and continues to influence materials science and environmental health. However, there is still uncertainly around the safety of these novel materials to humans and the environment; therefore, more life cycle data is needed. One analytical technique to gather information critical to the development of safe nanomaterials is to characterize the physicochemical properties of the nano-enabled product along various stages of the product life cycle. This research investigates two different products fortified with nanoscale titania relevant to the building and construction industry: (1) a white paint and (2) a lacquer formulation. Three brands of commercially available titanium dioxide (TiO2) nanoparticles were incorporated into labformulated paint and lacquer mixtures. These fortified products were subjected to simulated degradation processes (a.k.a. "wear-and-tear" scenarios) to mimic the real world. Unincorporated TiO2, as well as TiO2 incorporated "wornand-torn" powders, were processed and analyzed for physical, chemical, and toxicological characteristics. Electron microscopy confirmed the presence of nanoscale TiO2 particles in the painted and lacquered matrices for all three nanoparticle-types. Cell viability and reactive oxygen species (ROS) generation was measured in immortalized human lung epithelial cells (A549). Results from bioassays showed that ROS generation between unincorporated TiO2 particles and $\mathrm{TiO} 2$ incorporated paint powders showed little difference, but, the $\mathrm{TiO} 2$ incorporated lacquered powders demonstrated significantly lower ROS generation and cell death. Thus, the polymer-based lacquer mitigated tissue damage. Our results show that using a life cycle approach may help provide data - and by extension, an understanding - of nanomaterial properties in the context of developed consumer products.
\end{abstract}

Keywords: Nanocomposites; Nanomaterials; Titanium dioxide; Physicochemical characteristics; Cytotoxicity; Material characterization

\section{Introduction}

Engineered nanomaterials offer great advantages to the building industry by supporting sustainable development. It is well documented that the physical and chemical properties of nanometer-sized materials offer specific benefits over the same material in bulk form [1,2]. For example, in the building industry, engineered nanoparticles can increase resistance to ultraviolet damage, prevent degradation and fouling, and improve the rheology, hardness, and strength of construction materials [3]. In many cases, individual engineered nanoparticles are incorporated into larger composite products (e.g., cements, concretes, plastics, metal, or ceramics) which provide the benefits of nanotechnology, but with a generally-regarded decreased risk of direct particle exposure. To date, more than 250 products produced by over 100 companies incorporate nanocomposites into building or renovation plans with estimated revenues surpassing $\$ 1$ billion [6]. Although nanocomposites have been hypothesized to substantially decrease the potential for direct exposure to nanoparticles $[4,5]$, the potential for human and environmental risk along the various stages of the product value chain is uncertain. At manufacture, exposure potential is high due to airborne particle circulation; at formulation and product use, exposure is low due to particle containment within a matrix; at demolition, exposure potential is high, again, due to particle release from matrix; at landfill, exposure is low, again, due to particle agglomeration to environmental matter. Only a few laboratory studies have been designed and performed to test this concept [7].

The paint and lacquer industry, in particular, uses tons of engineered nanomaterials, annually. Titanium dioxide $\left(\mathrm{TiO}_{2}\right)$ nanoparticles have traditionally been incorporated in paint and lacquer formulations as a whitening agent and to provide properties such as improved durability, water repellence, and scratch resistance [8]. The global use of $\mathrm{TiO}_{2}$ for paint and surface applications alone exceeds 2.5 million tons annually with the specific use of nanoscale $\mathrm{TiO}_{2}$ conservatively estimated around 30,000 tons [9-11]. As a result, human exposure to these engineered nanoparticles is inevitable. The route and extent of particle exposure, however, is dependent upon the application and use of the nanoenabled product in real world scenarios [12-14].

While several studies have heavily investigated the physiochemical characteristics and material toxicity of pristine or unincorporated $\mathrm{TiO}_{2}$ nanoparticles [15], little is known about the effects of $\mathrm{TiO}_{2}$ nanoparticles incorporated into complex matrices, such as paint and lacquer formulations. More importantly, changes in physiochemical characteristics, potential exposure scenarios, and hazards of the intermediate materials are unknown and are in need of research emphasis [16]. The identification and characterization of engineered nanoparticles in complex matrices is a prerequisite to fill data gaps in risk assessments of human and environmental safety as nano-enabled products are developed. One way to gather information critical to

*Corresponding author: Christie M. Sayes, Department of Environmental Science, Baylor University, One Bear Place \#97266, Waco, Texas 76798-7266 USA, Tel: 254-710-3405; Fax: 254-710-3409; E-mail: Christie_sayes@baylor.edu

Received September 03, 2015; Accepted October 23, 2015; Published October 27, 2015

Citation: Sayes CM, Sooresh A, Meissner KE (2015) Physicochemical Characteristics of Two Prototypical Home-Use Consumer Products Containing Engineered Nanomaterials. J Environ Anal Toxicol 5: 326. doi:10.4172/2161 0525.1000326

Copyright: (c) 2015 Sayes CM, et al. This is an open-access article distributed under the terms of the Creative Commons Attribution License, which permits unrestricted use, distribution, and reproduction in any medium, provided the original author and source are credited. 
the development of safe nanomaterials is employing a product life cycle approach [17-20] which integrates product development with manufacturing and consumer/occupational exposure. Potential exposures in the form of precipitated particles from water waste or airborne particles from aerosolization processes are examples of byproducts from nano-enabled goods that could cause potential adverse health effects [21].

This research characterizes pristine, unincorporated, bulk $\mathrm{TiO}_{2}$ material and degraded, incorporated, nanoparticle-enabled byproducts. Three commercially available $\mathrm{TiO}_{2}$ nanoparticles were mixed into paint and lacquer formulations and applied onto industry standard substrates: paint on drywall and lacquer on hardwood panels. Simulated wear-and-tear scenarios were performed on each of the substrates. Pristine and worn-and-torn powders were then exposed to immortalized human lung epithelial cells to investigate the effect on cellular viability and reactive oxygen species (ROS) generation. The impact of this research will help enable sustainable opportunities of nanotechnology in the built environment.

\section{Materials and Methods}

\section{Nanoparticles used in the study}

Three commercially available $\mathrm{TiO}_{2}$ nanoparticles currently used for applications in industrial coatings were used. These pristine nanoparticles differed in surface treatment and were designated as $\mathrm{TiO}_{2}-1$, a silica/alumina-treated rutile pigment, $\mathrm{TiO}_{2}-2$, a zirconia/ alumina-treated rutile pigment, and $\mathrm{TiO}_{2}-3$, an aluminum hydroxide/ silica- treated rutile pigment. Materials $\mathrm{TiO}_{2}-1$ and $\mathrm{TiO}_{2}-2$ were obtained from Tronox Limited with trade names CR-826 and CR828 , respectively. The third material, $\mathrm{TiO}_{2}-3$, was acquired from Cristal Global with trade name Tiona 596. All $\mathrm{TiO}_{2}$ nanoparticles were multipurpose grade rutile pigments having excellent optical properties and high durability. The properties of the three focal $\mathrm{TiO}_{2}$ nanoparticles used in this study are listed in Table 1.

\section{Nano-enabled products}

To mimic real word applications, the three $\mathrm{TiO}_{2}$ nanoparticles were incorporated into paint and lacquer coatings. The laboratoryformulated coatings were prepared as described below.

Paint on drywall: The paint formulation used included base paint (with and without $\mathrm{TiO}_{2}$ ) mixed via commercial specifications [22]. EcoVAE Interior Quality Flat formulation was used as a reference for base paint (Celanese Corp., Irving, TX) [23]. Per the specifications, water, latex, and thickener were mixed using an air mixer and Cowles blade for 30 minutes. While mixing, other additives i.e., defoamer, dispersant, surfactant, fillers, and pigment extenders (except $\mathrm{TiO}_{2}$ ) were added to the mixture and well blended. Finally, $16 \mathrm{wt} \%$ pristine $\mathrm{TiO}_{2}$ nanoparticles were added to the base paint formulation [23]. Base paint without $\mathrm{TiO}_{2}$ served as a control.

In an effort to validate this laboratory-formulated paint, a commercial water-based interior flat paint sample was included in this study (Olympic, PPG Industries, Pittsburgh, PA). This commercial paint sample was mixed using the air mixer and Cowles blade described above to ensure a well-blended material with no settling.

As a final step, paint formulations were poured into cast as a 25 mil (mil is an industry specific term where $1 \mathrm{mil}$ is equivalent to 0.0254 $\mathrm{mm}$ ) wet film using a Gardco 8-path slot coater to achieve uniform paint thickness on the drywalls. This coated surface was then air-dried at room temperature for 2 days. An average paint thickness of $0.20 \mathrm{~mm}$, equivalent to $\sim 8$ mils was observed.

Lacquer on wood panels: The lacquer coatings were prepared by the addition of $1 \mathrm{wt} \%$ of DPT (diphenyl (2,4,6-trimethylbenzoyl) phoshpine oxide) to a polyester based resin (polyester tetraacrylate, also known as acrylic ester). To this resin, $2 \mathrm{wt} \% \mathrm{TiO}_{2}$ was incorporated. Resin without $\mathrm{TiO}_{2}$ served as a control. A clean and dry wood panel was coated with polyester resin and laminated to a polyethylene terephthalate (PET) film. The wood surface was then cured for 180 seconds at $\lambda=365 \mathrm{~nm}$. Once cured, the PET film could be easily stripped off leaving the final product coated and completely dry. A second coat was applied to ensure adequate coating thickness.

The $16 \mathrm{wt} \% \mathrm{TiO}_{2}$ addition in paints and the $2 \mathrm{wt} \% \mathrm{TiO}_{2}$ addition in wood coatings were based on industrial specifications [24-26].

\section{Wear-and-tear process}

The nano-enabled paint on drywall and lacquer on wood panels were subjected to wear-and-tear scenarios to mimic real world use and demolition [16]. The Taber test is one of the most commonly employed techniques for simulating the abrasive damage to surfaces $[27,28]$. The surfaces of the $\mathrm{TiO}_{2}$-enabled paint on drywall and lacquer on wood panels were abraded using a jumbo collet and Taber Abraser 5900 reciprocating machine (Testing Machines Inc., New Castle, Delaware). Ten abrasive cycles with a rotation speed of 60 cycles/minute and a normal force of $10 \mathrm{~N}$ were employed for each sample. Abrasion was caused by friction at the contact line between the sample surface and the jumbo collet. Powders from each sample were collected in vials.

The steps involved in the paint formulation and subsequent wear-and-tear process on the drywalls are depicted in Figure 1 in the Supporting Information. The worn-and-torn paint powders were designated as base paint (i.e., no $\mathrm{TiO}_{2}$ ), base paint plus $\mathrm{TiO}_{2}-1$, base paint plus $\mathrm{TiO}_{2}-2$, and base paint plus $\mathrm{TiO}_{2}-3$.

The steps involved in the lacquer on wood panels and subsequent wear-and-tear processes are depicted in Figure 2 in the Supporting Information. The worn-and-torn lacquer powders were designated as uncoated wood (i.e., no $\mathrm{TiO}_{2}$ ), wood plus $\mathrm{TiO}_{2}-1$, wood plus $\mathrm{TiO}_{2}-2$ and wood plus $\mathrm{TiO}_{2}-3$.

\section{Material characterization}

The following material characterization techniques were used to analyze the pristine, unincorporated $\mathrm{TiO}_{2}$ nanoparticles (as described in Section 2.1) as well as the worn-and-torn $\mathrm{TiO}_{2}$-enabled paint and lacquered wood powders (as described in Section 2.3).

Transmission Electron Microscopy (TEM): Samples were suspended in ultra- pure water in preparation of TEM analysis. Microscope grids were prepared by dropping

$3 \mu \mathrm{L}$ of each suspended sample on to a 200 mesh copper grid (Ted Pella, Inc., Redding, CA) and dried overnight. Samples were imaged using Hitachi H-7000 electron microscope operated at an accelerating voltage of $100 \mathrm{kV}$. Images were recorded using a Gatan CCD camera and 4pi Revolution software.

Scanning Electron Microscopy (SEM): Samples for SEM analysis were deposited onto a carbon adhesive surface affixed to SEM stubs and coated with gold/palladium for 2 minutes using a Hummer sputtering system (Anatech, Ltd., Battle Creek, MI). Samples were imaged using a FEI Quanta 200 environmental scanning electron microscope. Images were recorded using high vacuum mode, typically $15 \mathrm{kV}$, spot size 2.5 , and a working distance of $10 \mathrm{~mm}$. Elemental analysis was performed 
Citation: Sayes CM, Sooresh A, Meissner KE (2015) Physicochemical Characteristics of Two Prototypical Home-Use Consumer Products Containing Engineered Nanomaterials. J Environ Anal Toxicol 5: 326. doi:10.4172/2161-0525.1000326

Page 3 of 9

\begin{tabular}{|c|c|c|c|}
\hline Property & $\mathrm{TiO}_{2}-1$ & $\mathrm{TiO}_{2}-2$ & $\mathrm{TiO}_{2}-3$ \\
\hline \multicolumn{4}{|c|}{$\begin{array}{ll}\text { - } & \text { Interior and exterior industrial coatings } \\
\text { - } & \text { Interior and exterior architectural coatings } \\
\text { - } & \text { Marine finishes coatings } \\
\text { - } & \text { Pater and solvent-based industrial coatings } \\
\text { - } & \text { Gender coatings } \\
& \text { Genal industrial coatings }\end{array}$} \\
\hline $\begin{array}{c}\text { Surface treatment } \\
\text { (as specified by supplier) }\end{array}$ & $\begin{array}{l}\text { Dense silica/alumina-treated } \\
\text { rutile pigment }\end{array}$ & Zirconia/alumina- treated rutile pigment & $\begin{array}{l}\text { Aluminum hydroxide/silica } \\
\text { treated rutile pigment }\end{array}$ \\
\hline $\begin{array}{c}\mathrm{TiO}_{2} \text { content } \\
\text { (as specified by supplier) }\end{array}$ & $93 \%$ & $95 \%$ & $94 \%$ \\
\hline $\begin{array}{c}\text { Durability } \\
\text { (as specified by supplier) }\end{array}$ & Very high & High & - \\
\hline $\begin{array}{c}\text { Average particle size } \\
\text { (as specified by supplier) }\end{array}$ & $200 \mathrm{~nm}$ & $190 \mathrm{~nm}$ & - \\
\hline $\mathrm{pH}$ & 8.0 & 8.0 & 8.0 \\
\hline $\begin{array}{l}\text { Zeta potential (mV) } \\
\text { (measured in- house) }\end{array}$ & $21.2 \pm 0.20$ & $31.1 \pm 0.72$ & $19.2 \pm 0.62$ \\
\hline
\end{tabular}

Table 1: Material properties of the three pristine $\mathrm{TiO}_{2}$ nanoparticles used in the study.
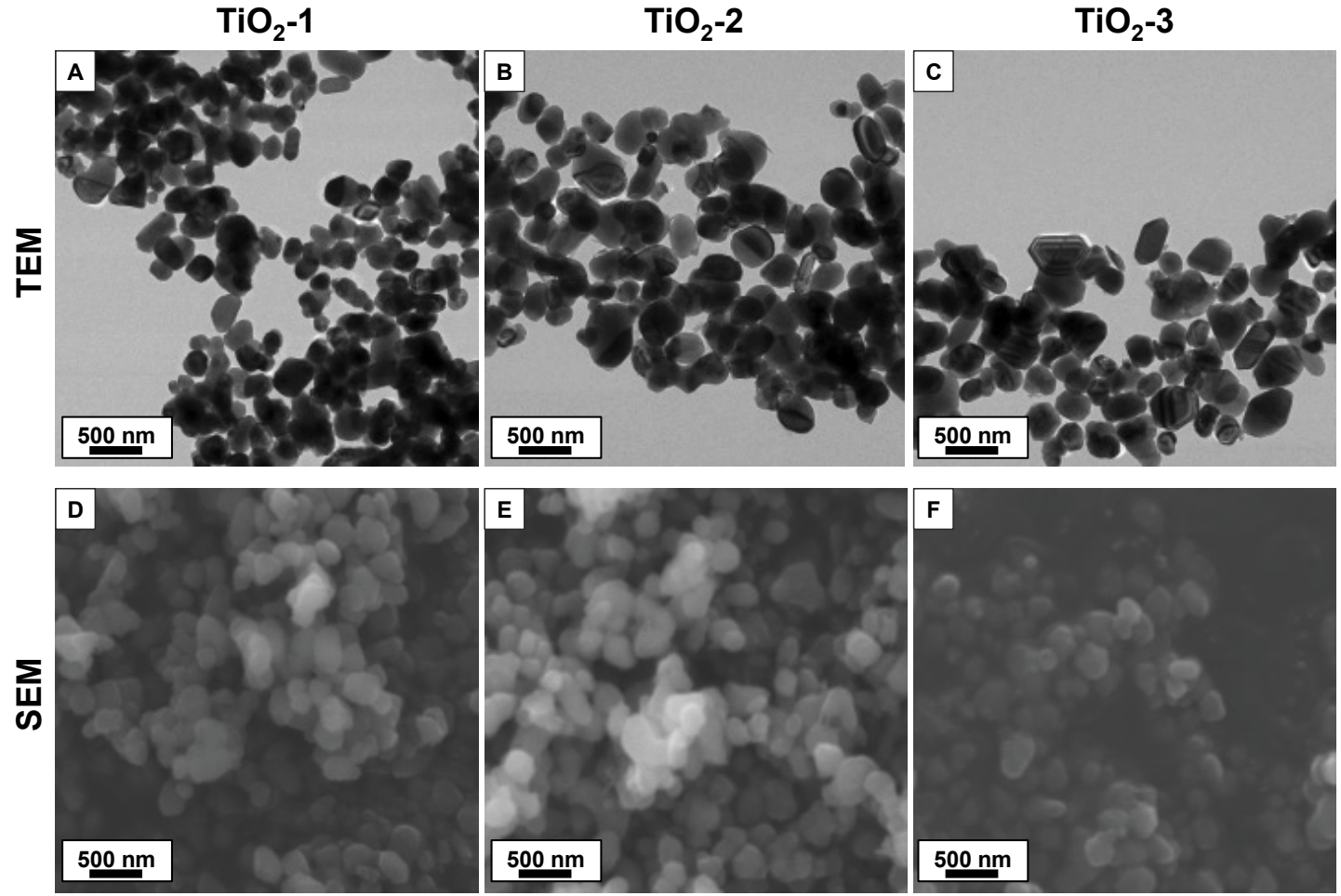

Figure 1: TEM and SEM of pristine $\mathrm{TiO}_{2}$ nanoparticles. Transmission electron micrographs (top) and scanning electron micrographs (bottom) of the pristine TiO nanoparticles. Three different $\mathrm{TiO}_{2}$ nanoparticles were used in the study, and designated as $\mathrm{TiO}_{2}-1, \mathrm{TiO}_{2}-2$ and $\mathrm{TiO}_{2}-3$. (A) TEM of $\mathrm{TiO}_{2}-1$, (B) $\mathrm{TEM}$ of $\mathrm{TiO}_{2}-2$, (C) TEM of $\mathrm{TiO}_{2}-3$, (D) SEM of $\mathrm{TiO}_{2}-1$, (E) SEM of $\mathrm{TiO}_{2}-2$ and (F) SEM of $\mathrm{TiO}_{2}-3$.

for each sample using the attached X-ray detector and Inca X-sight software (Oxford Instruments X-ray Technology) was used to process the EDX spectra.

Fourier Transform Infrared Spectroscopy (FTIR): Chemical compositions of samples were probed using a Thermo-Fischer Smart Orbit-Single Bounce ATR (Thermo Scientific, Madison, WI) using a Nicolet 6700 FTIR in the $400-4000 \mathrm{~cm}^{-1}$ range. Spectra were recorded in transmission mode with a resolution of $4 \mathrm{~cm}^{-1}$. Thirty-two scans were collected and averaged for each spectrum. 
Citation: Sayes CM, Sooresh A, Meissner KE (2015) Physicochemical Characteristics of Two Prototypical Home-Use Consumer Products Containing Engineered Nanomaterials. J Environ Anal Toxicol 5: 326. doi:10.4172/2161-0525.1000326

TEM
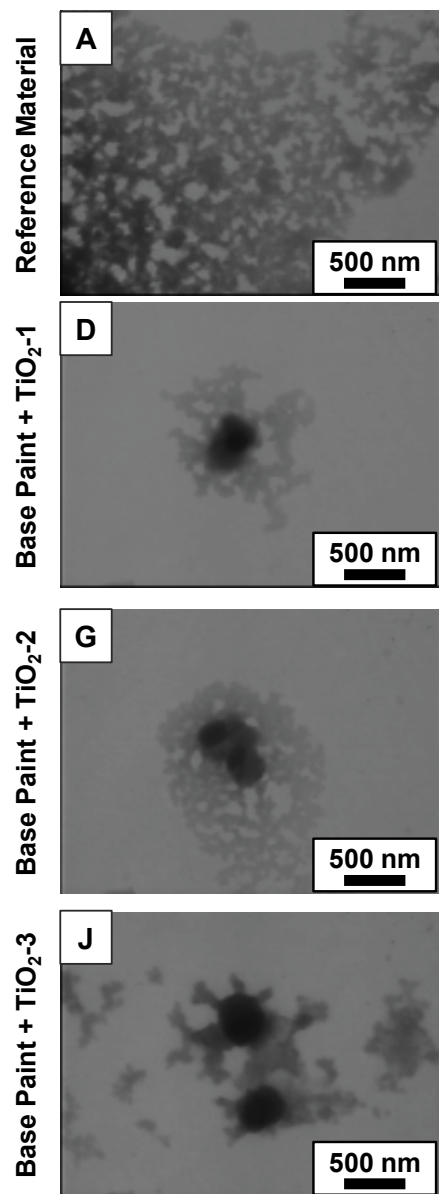

SEM
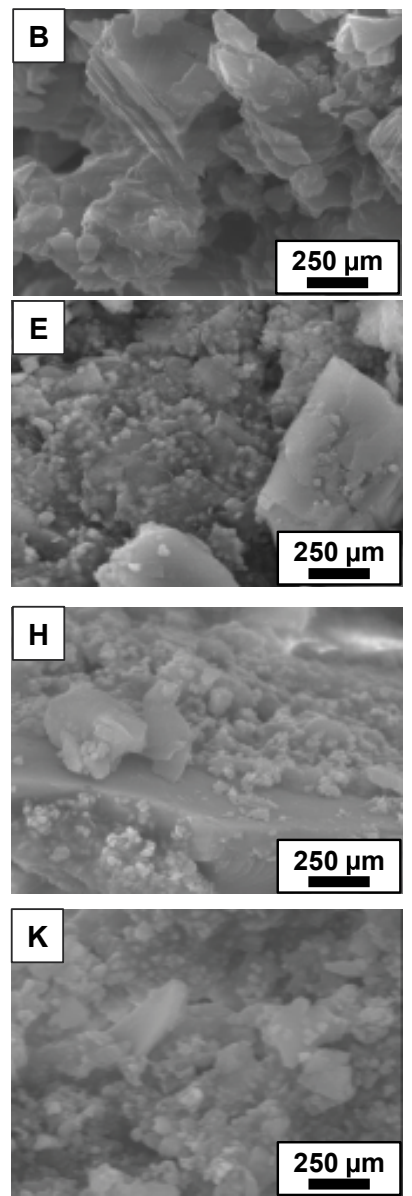

EDX
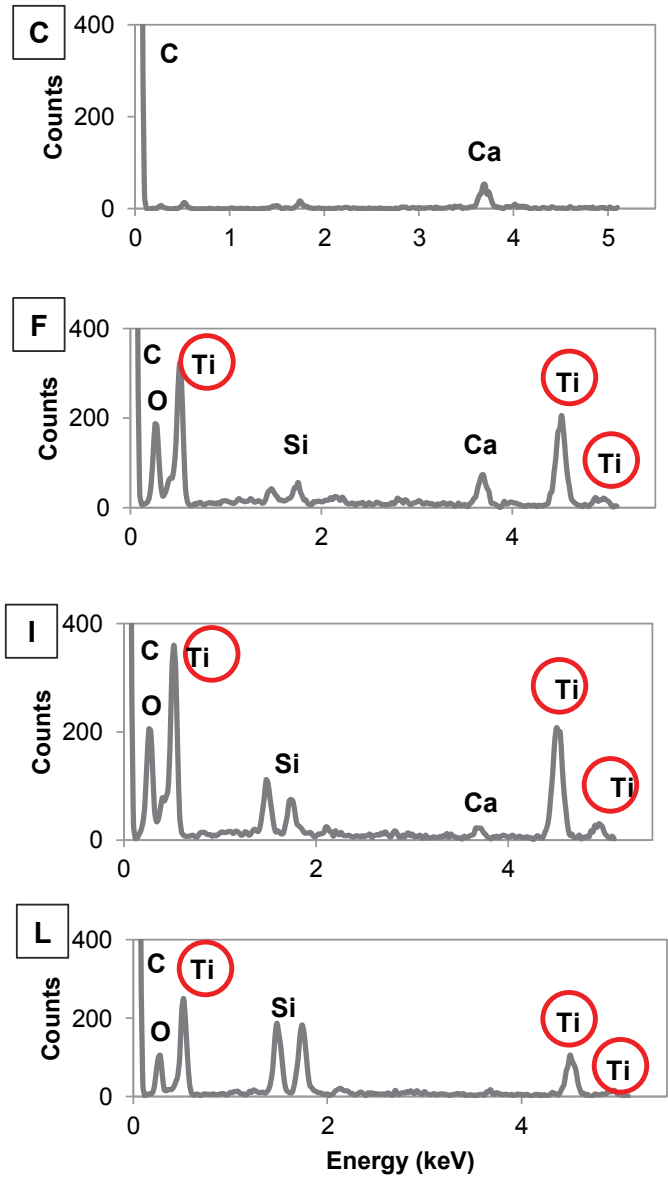

Figure 2: TEM, SEM and EDX spectra of particles collected after wear-and-tear of painted drywall surfaces. (A) TEM of worn-and-torn reference material particles, (B) SEM of worn-and-torn reference material particles, (C) EDX of worn-and-torn reference material particles; (D) TEM of worn-and-torn base paint plus $\mathrm{TiO}_{2}-1$ particles, (E) SEM of worn-and-torn base paint plus $\mathrm{TiO}_{2}-1$ particles, (F) EDX of worn-and-torn base paint plus TiO -1 particles; (G) TEM of wornand-torn base paint plus $\mathrm{TiO}_{2}-2$ particles, $(\mathrm{H})$ SEM of worn-and-torn base paint plus $\mathrm{TiO}_{2}-2$ particles, (I) EDX of worn-and-torn base paint plus TiO -2 particles; (J) TEM of worn-and-torn base paint plus $\mathrm{TiO}_{2}-3$ particles, (K) SEM of worn-and-torn base paint plus $\mathrm{TiO}_{2}-3$ particles and (L) EDX of worn-and-torn base paint plus $\mathrm{TiO}_{2}-3$ particles.

\section{Generation of reactive oxygen species}

Cell cultures: Cellular response studies were probed using immortalized human lung epithelial (A549) cells (ATCC, Manassas, VA). Cells were maintained in F-12K medium supplemented with $10 \%$ fetal bovine serum and $1 \%$ penicillin and streptomycin. Cells were cultured at $37^{\circ} \mathrm{C}$ in a humidified atmosphere with $5 \% \mathrm{CO} 2$ and passaged every 3 days. Passage numbers $2-10$ were used in the experiments.

Cell viability: A549 cells were seeded with $1 \times 10^{4} \mathrm{cells} / \mathrm{cm}^{2}$ in 24 well plates in complete growth medium and allowed to proliferate for 48 hours until $80 \%$ confluent. Cells were gently washed with phosphate buffered saline (HyClone, Logan, UT), followed by exposure to increasing concentrations $(0,0.1,1,10,100$, and $1000 \mathrm{ppm})$ of the three pristine $\mathrm{TiO}_{2}$ nanoparticles in complete medium and incubated for 24 hours. Cell viability was assessed using trypan blue exclusion assay via the Countess Automated Cell Counter (Invitrogen) as per the manufacturer's instructions. The purpose of performing a doseresponse cytotoxicity study using the pristine $\mathrm{TiO}_{2}$ samples was to determine a relevant concentration to subsequently perform reactive oxygen species measurements.
Intracellular ROS measurement: DCFH-DA $\left(2^{\prime}, 7^{\prime}\right.$-dichlorofluorescein diacetate) was used to measure the levels of intracellular reactive oxygen species (Cell Biolabs, Inc.) after exposure to $\mathrm{TiO}_{2}$ in pristine and incorporated form (dosing concentration was $50 \mathrm{ppm}$ or $\mu \mathrm{g} / \mathrm{L})$. Cells were seeded with $1 \times 10^{4} \mathrm{cell} / \mathrm{cm}^{2}$ in a 96 -well plate in complete growth medium. Upon reaching $80 \%$ confluency, cells were gently washed with PBS followed by treatment with $100 \mu \mathrm{M}$ DCFH-DA and incubated at $37^{\circ} \mathrm{C}$ for $30 \mathrm{~min}$. Cells were then exposed to pristine unincorporated $\mathrm{TiO}_{2}$ nanoparticles, worn-and-torn paint samples, or worn-and-torn lacquered wood samples and incubated for 24 hours. Hydrogen peroxide $(1000 \mu \mathrm{M})$ was used as the positive control. Unexposed cells in complete medium served as a negative control. After the 24-hour incubation, fluorescence was measured at 480 and $530 \mathrm{~nm}$ (excitation and emission, respectively) using a fluorescence plate reader (Synergy Mx Multi-Mode Microplate Reader, BioTek Instruments, Inc., Winooski, VT). The study was designed for an $n=8$ replicates per treatment and each experiment were performed in triplicate. 


\section{Statistical analysis}

Each value represents the mean of at least three separate analyses plus or minus the standard error of the mean. Multiple comparisons were performed using analysis of variance (ANOVA) followed by posthoc testing if $\mathrm{p}<0.05$.

Differences between treatment groups were analyzed via the Turkey-Kramer Multiple Comparisons test, a parametric analyses, comparing all pairs of columns to untreated cells.

Probability values of $\mathrm{p}<0.05$ were considered to be statistically significant. Statistical analyses were performed using INSTAT software v 3.0 (GraphPad, Inc., San Diego, CA).

\section{Results and Discussion}

\section{Physicochemical analyses of TiO2-enabled products}

$\mathrm{TiO}_{2}$ particles primarily exist in two morphological crystalline forms, rutile or anatase, with each phase possessing a unique crystal structure $[29,30]$. The differences in crystal structures cause differences in mass densities and electronic band structures, and consequently affect their photoactivity [30]. In general, rutile is claimed to be less photoactive than anatase due to surface defects and thus commonly used as a white pigment in the coating industry [29,31]. To improve pigment dispersion, the surface of $\mathrm{TiO}_{2}$ is treated with alumina, silica, zirconia, aluminum phosphates of other metals or often a combination of these minerals [32]. Surface modifications with inorganic hydrates decrease the photoactivity of titania pigments by increasing electronhole recombination sites [33]. Hence, the surface treatment technique dictate the photoactivity of titania pigments and the effectiveness of the coating determines the degree of photoactivity [34]. From a toxicological point of view, surface modifications physically inhibit the diffusion of oxygen and thereby reduce the generation of free radicals. Other advantages of surface treatments include improved wetting ability in different media (water, solvent, and polymer) and improved compatibility with binder and color stability [35].

The life cycle or product value chain for engineered nanomaterials incorporated into paints and other coatings has four main stages in which human exposure may occur: (1) manufacture/production of raw materials, (2) product formulation, (3) product use, and (4) product demolition and disposal. The exposure risks in these stages include the release of pristine particles or formulated composites as industrial air emissions, wastewater processes, or trash. In regard to human exposure, release from worn-and-torn formulated composites, as in the case of natural weathering or "do-it- yourself" home projects, into aerosolized particulate matter in the breathing zone or solid particulates that deposit on the skin's surface are major sources of concern. Further identification of potential hazards from such sources requires toxicity testing using appropriate model test systems depending on the type of exposure.

The three pristine, unincorporated $\mathrm{TiO}_{2}$ nanoparticles chosen for this study are currently used in paint products. Designated as $\mathrm{TiO}_{2}-1$, $\mathrm{TiO}_{2}-2$, and $\mathrm{TiO}_{2}-3$, these particles were incorporated into paint and lacquer formulations, applied to drywall and wood, respectively, and subjected to simulated wear-and-tear scenarios. This wear-and- tear simulation was designed to mimic a consumer sanding a surface (Stage 4 ), which are analyzed and compared to the pristine particles (Stage 1) [16].

\section{Material characterization}

Images from electron microscopy reveal critical information about the particle size, shape, aggregation, and morphology. Energy dispersive X-ray spectroscopy (EDX) confirms the elemental composition of each sample. Figure 1 shows the transmission and scanning electron micrographs of the three pristine $\mathrm{TiO}_{2}$ samples. These micrographs confirm primary particle size to be $200 \mathrm{~nm}$ for all three $\mathrm{TiO}_{2}$ nanoparticle- types.

Figure 2 shows the TEM, SEM and EDX spectra of the wornand-torn paint powders. Micrographs of the base paint formulations mixed with $\mathrm{TiO}_{2}$ nanoparticles (i.e., base paint plus $\mathrm{TiO}_{2}$ ) indicate $\mathrm{TiO}_{2}$ nanoparticles embedded in the matrix. The micrographs also show the reference material (i.e., base paint without $\mathrm{TiO}_{2}$ ) is devoid of $\mathrm{TiO}_{2}$ particles. Micrographs suggest aggregate particle size to be approximately $600 \mathrm{~nm}$ for all three $\mathrm{TiO}_{2}$ nano-enabled paint products. Additionally, the EDX spectra confirm the absence of $\mathrm{TiO}_{2}$ in the reference material and the presence of $\mathrm{TiO}_{2}$ in other samples with characteristic peaks of $\mathrm{Ti}(0.45,4.5$ and $4.9 \mathrm{keV})$. The background material also shows representative peaks for carbon and oxygen. The strong Si peak in samples can be attributed to the paint ingredient Diafil 525, which contains silicon and silica. The calcium (Ca) peak is present in native drywall in the form of calcium carbonate.

Figure 3 shows the TEM, SEM and EDX spectra of the wornand-torn lacquered wood samples. As shown in the micrographs, the reference sample (i.e., uncoated wood) does not have any characteristic $\mathrm{TiO}_{2}$ particles while all the other samples (lacquered wood with $\mathrm{TiO}_{2}$ ) show $\mathrm{TiO}_{2}$ nanoparticles embedded in the complex wood matrix. Micrographs reveal aggregate particle sizes are approximately 200 $\mathrm{nm}$ and approximately $600 \mathrm{~nm}$ for all three $\mathrm{TiO}_{2}$ nano-enabled wood samples. Samples with incorporated nanoparticles clearly indicate the presence of $\mathrm{TiO}_{2}$ nanoparticles in the EDX spectra. Because only $2 \mathrm{wt} \%$ $\mathrm{TiO}_{2}$ was included in the resin matrix, the EDX peaks are not as strong as the paint samples $\left(16 \mathrm{wt} \% \mathrm{TiO}_{2}\right)$, but the micrographs confirm the presence of the nanoparticles.

Taken together, these analytical techniques confirm the presence of $\mathrm{TiO}_{2}$ embedded in the complex paint formulations on the drywall and wood coatings after the wear-and-tear process. Using electron microscopy, the individual primary particles are clearly distinguishable, thus providing motivation to investigate the potential impacts of exposure to powders released from nano-enabled products. Nanoparticles incorporated into composites can be abraded and dislodged from the parent material. These individual nanoparticles - while not identical to the original engineered raw materials- are still reactive on their surface and free to interact with surrounding environments independent of the composite.

In addition to electron microscopy, unincorporated and incorporated $\mathrm{TiO}_{2}$ samples were analyzed using Fourier transform infrared spectroscopy (FTIR). The fundamental vibrations of $\mathrm{TiO}_{2}$ appear in the in the low energy region of the infrared spectra. A peak in the $500-520 \mathrm{~cm}^{-1}$ range can be attributed to the presence of $\mathrm{TiO}_{2}$ in the samples [36-39]. Additionally, bands in the low energy region between $340-520 \mathrm{~cm}^{-1} \mathrm{can}$ be assigned to the stretching vibrations of the Ti-O-Ti bonds $[36,40,41]$.

Figures $4 \mathrm{a}, \mathrm{b}$ and $\mathrm{c}$ show the FTIR spectra of the pristine $\mathrm{TiO}_{2}$ nanoparticles, the worn-and-torn paint samples and the worn-andtorn lacquered wood samples, respectively. On analyzing the spectral peak positions, the characteristic structure of $\mathrm{TiO}_{2}$ in the $340-520 \mathrm{~cm}^{-1}$ range is observed in all three pristine $\mathrm{TiO}_{2}$ samples (Figure 4a). 
TEM
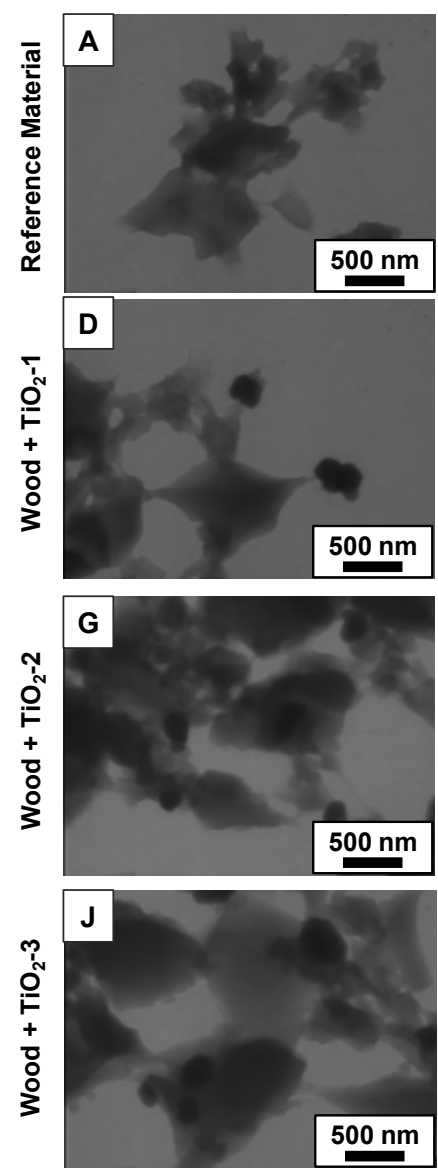

SEM
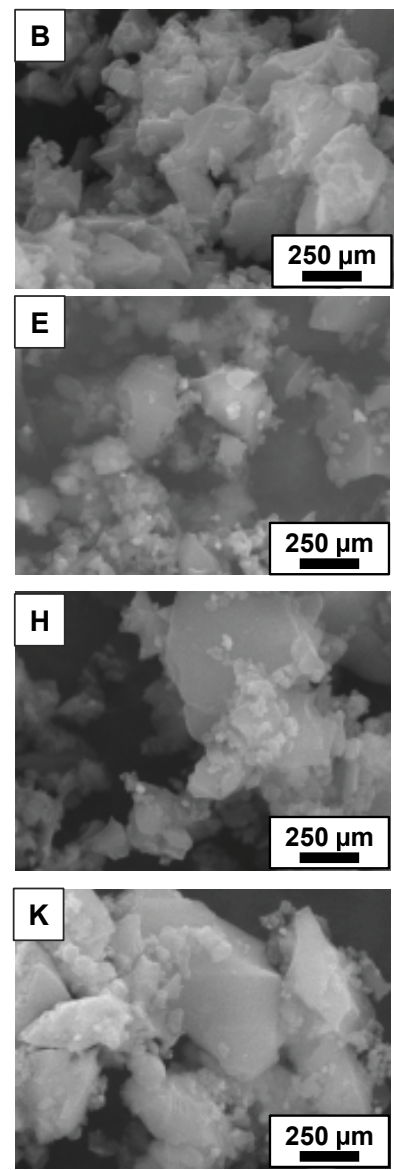

EDX
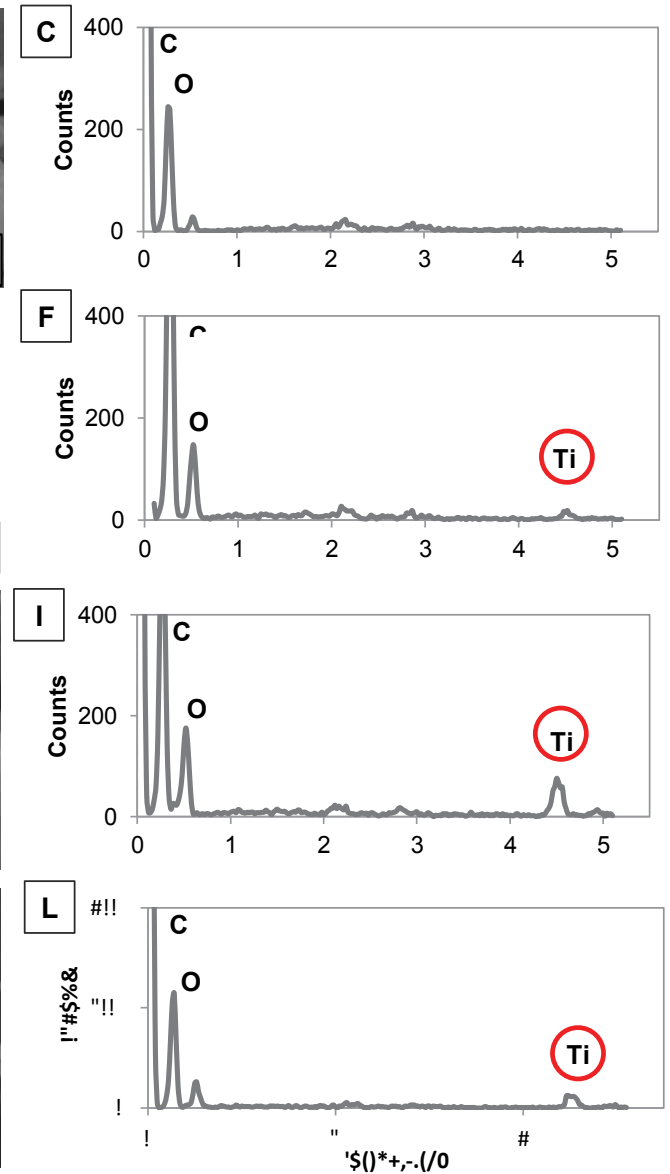

Figure 3: TEM, SEM and EDX spectra of particles collected after wear-and-tear of coated lacquered wood surfaces. (A) TEM of worn-and-torn reference material particles, (B) SEM of worn-and-torn reference material particles, (C) EDX of worn-and-torn reference material particles; (D) TEM of worn-and-torn lacquered wood plus $\mathrm{TiO}_{2}-1$ particles, (E) SEM of worn-and-torn lacquered wood plus $\mathrm{TiO}_{2}-1$ particles, $(\mathrm{F})$ EDX of worn-and-torn lacquered wood plus TiO -1 particles; (G) TEM of worn-and-torn lacquered wood plus $\mathrm{TiO}_{2}-2$ particles, $(\mathrm{H}) \mathrm{SEM}$ of worn-and-torn lacquered wood plus TiO -2 particles, (I) EDX of worn-and-torn lacquered wood plus $\mathrm{TiO}_{2}-2$ particles; (J) TEM of worn-and-torn lacquered wood plus $\mathrm{TiO}_{2}-3$ particles, (K) SEM of worn-and-torn lacquered wood plus $\mathrm{TiO}_{2}-3$ particles and (L) EDX of worn-and-torn lacquered wood plus $\mathrm{TiO}_{2}-3$ particles.

Figure $4 \mathrm{~b}$ shows the FTIR spectra of the worn-and-torn paint samples. The FTIR spectrum of the base paint with no $\mathrm{TiO}_{2}$ is also shown. The characteristic structure of $\mathrm{TiO}_{2}$ in the $340-520 \mathrm{~cm}^{-1}$ range is present in all three worn-and-torn paint samples but absent in the base paint spectrum. In order to further quantify this $\mathrm{TiO}_{2}$ peak, the worn- and-torn paint samples were corrected for background using the base paint sample as the reference spectra. Figure 3 in the Supporting Information overlays the FTIR spectra of the three pristine $\mathrm{TiO}_{2}$ nanoparticles to the corresponding worn-and-torn paint plus $\mathrm{TiO}_{2}$ samples. The peak at approximately $500 \mathrm{~cm}^{-1}$ is clearly visible in all three worn-and-torn paint samples and matches the pristine sample spectra. Therefore, in addition to microscopy techniques such as TEM and SEM, and elemental analysis via SEM- EDX, these FTIR spectra further confirm the presence of $\mathrm{TiO}_{2}$ in the complex worn-and- torn paint matrix. At $16 \mathrm{wt} \% \mathrm{TiO}_{2}$ included in the paint formulations; FTIR is able to detect the presence of the characteristic $\mathrm{TiO}_{2}$ peaks in all the worn-and-torn paint samples.

Figure $4 \mathrm{c}$ shows the FTIR spectra of the worn-and-torn lacquered wood samples. The FTIR spectrum of the wood with no $\mathrm{TiO}_{2}$ is also shown. From these spectra it is evident that the characteristic structure of Ti at $520 \mathrm{~cm}^{-1}$ is not prominent in all three worn-and-torn wood samples. Similar to the paint samples, the worn-and-torn wood samples were also corrected for background using the wood with no $\mathrm{TiO}_{2}$ sample as the reference spectra to quantify the presence of $\mathrm{TiO}_{2}$. Figure 4 in the Supporting Information overlays the FTIR spectra of the three pristine $\mathrm{TiO}_{2}$ nanoparticles to the corresponding worn-andtorn wood plus $\mathrm{TiO}_{2}$ samples. After correcting for background, the characteristic peak of Ti at $520 \mathrm{~cm}^{-1}$ is still not prominent in any of the worn-and-torn lacquered wood samples. Because the samples contain only $2 \mathrm{wt} \% \mathrm{TiO}_{2}$ in this formulation, the signal appears to be below the detection limit of the FTIR system. As a result, the signal from the $\mathrm{TiO}_{2}$ in the worn-and-torn lacquered wood matrix is not visible by FTIR, but is detectable by other material characterization techniques such as TEM, SEM and SEM-EDX which confirmed the presence of $\mathrm{TiO}_{2}$ in the complex worn-and- torn matrix.

\section{Generation of reactive oxygen species}

As with any new technology, the identification of potential health risks is a prerequisite for a cost-benefit analysis of new products. Studies suggest some nanomaterials can affect biological behaviors at 

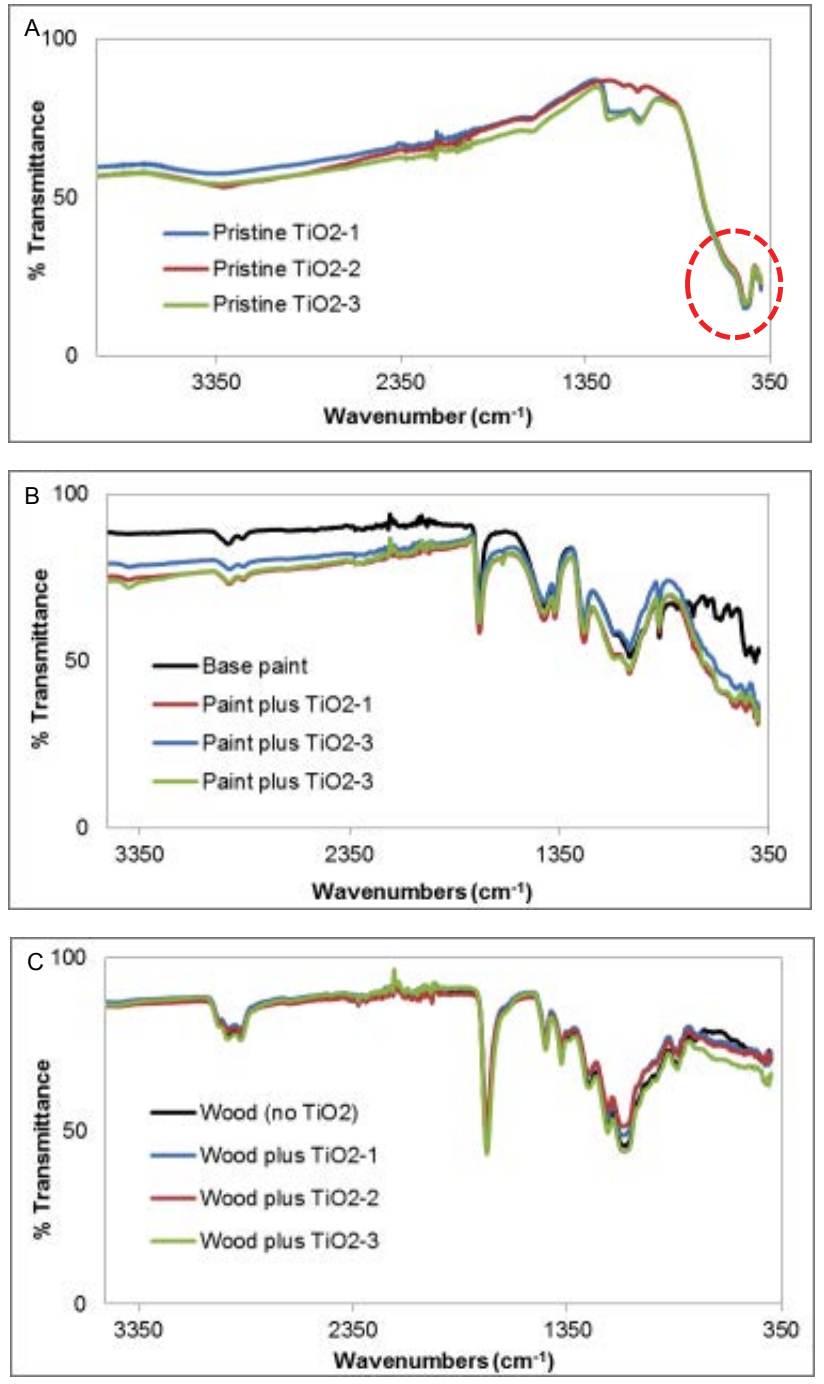

Figure 4: FTIR spectra. (A) Pristine $\mathrm{TiO}_{2}$, (B) Particles collected from worn-and-torn paint surfaces and (C) Particles collected from worn-and-torn lacquered wood surfaces.

the cellular level (e.g., decreased viability, increased reactive oxygen species (ROS) generation). Human and environmental health risks can be determined through assessment of the hazards posed and the potential for exposure to the nanomaterials in various life cycle stages. The most likely route of exposure to nanomaterials used in consumer products is inhalation by the occupational worker $[42,43]$. As the wearand-tear simulation of this study produced airborne powders in the socalled use stage, inhalation is also a likely route of consumer exposure.

A549 cells (a model lung system used to gauge the differential toxicological responses within a large set of material samples) were exposed for 24 hours to increasing concentrations of all three pristine $\mathrm{TiO}_{2}$ nanoparticles $(0,0.1,1,10,100$, and $1000 \mathrm{ppm})$. Based on the cellular response to these doses, a medium dose was chosen as the primary dosing concentration for subsequent ROS generation evaluation. The results of the trypan blue exclusion assay are summarized in Figure 5a. Cells exhibit a fairly monotonic doseresponse relationship upon exposures to all three nanoparticle- types.
Cellular viability is significantly reduced $(\mathrm{p}<0.01)$ as compared to untreated cells at the highest dose of $1000 \mathrm{ppm}$ for all three $\mathrm{TiO}_{2}$ types. Since cellular viability was unaltered at doses of $0.1,1$ and $10 \mathrm{ppm}$ (and significantly altered at the highest dose of $1000 \mathrm{ppm}$ ), the $100 \mathrm{ppm}$ dose was selected as the primary dosing concentration for ROS evaluation.

Recent evidence indicates that the possible mechanism of $\mathrm{TiO}_{2}$ nanoparticle-induced toxicity involves DNA damage via oxidative stress [21]. ROS production of $\mathrm{TiO}_{2}$ nanoparticles in their unincorporated and incorporated forms was tested in vitro. Cellular generation of ROS was measured after a 24-hour exposure to pristine $\mathrm{TiO}_{2}$, worn-andtorn paint samples, and worn-and-torn lacquered wood samples. Data were normalized to the appropriate control values and these results are summarized in Figures 5b, $\mathrm{c}$ and d. Statistically significant increase in oxidant production as measured via increased DCF fluorescence was observed with all three pristine $\mathrm{TiO}_{2}$ nanoparticles (Figure 5b). The ROS generation in the $\mathrm{TiO}_{2}-1, \mathrm{TiO}_{2}-2$ and $\mathrm{TiO}_{2}-3$ samples was 1.72 , 1.96 , and 1.65 fold greater than the unexposed control, respectively. The calculated $\mathrm{TiO}_{2}$ particle component after exposure of worn-andtorn materials to these cells was $8 \mu \mathrm{g} / \mathrm{L}(16 \%$ by weight of $50 \mu \mathrm{g} / \mathrm{L})$ for the paint product and $1 \mu \mathrm{g} / \mathrm{L}(2 \%$ by weight of $50 \mu \mathrm{g} / \mathrm{L}$ for the polymer material). The results of the ROS production from the worn-and-torn paint and lacquered wood samples are shown in Figure $5 \mathrm{c}$ and d. Only two out of the three worn- and-torn paint samples containing $\mathrm{TiO}_{2}$ (i.e., base paint plus $\mathrm{TiO}_{2}-2$ and base paint plus $\mathrm{TiO}_{2}-3$ ) exhibited significant increase in intracellular oxidants compared to the control. This may be due to differential adhesion, chemical attraction, or wetting of the paint matrix to the $\mathrm{TiO}_{2}$ nanoparticle surface. The water-based paint emulsion wets particles differently based on surface chemistries, thus the different particle-types may reside in different phases of the emulsion. When the paint dries, one particle-type may be "coated" with organic phases and thus not cause ROS generation while other particles may have simply dried as a mixture and still have active sites. In contrast, the worn- and-torn lacquered wood samples containing $\mathrm{TiO}_{2}$ did not cause any significant ROS generation in comparison to the control; however there was a significant difference among the three worn-and-torn lacquered wood samples as wood plus $\mathrm{TiO}_{2}-3$ showed lower ROS generation compared to wood plus $\mathrm{TiO}_{2}-1$ and wood plus $\mathrm{TiO}_{2}-2$ (Figure 5d).

\section{Commercial paint}

An off-the-shelf commercial paint was purchased and used in this study. This product was a water-based interior flat paint (Valspar White ColorStyle Interior Flat Wall Paint, 44-26300) and served as a comparison to our formulated nano-enabled paints. Paint on drywall samples were made, allowed to cure, and underwent the wear-and-tear simulation in the same fashion as the laboratory-formulated versions. The transmission electron micrograph, scanning electron micrograph and elemental analysis confirm the presence of $\mathrm{TiO}_{2}$ in the worn-andtorn commercial paint particles (Figure 6). The $\mathrm{TiO}_{2}$ nanoparticles were also of a similar particle size as compared to the nano-enabled paint formulated products in Figure 2. Furthermore, the ROS generation in A549 cells upon exposure to this commercial paint sample exhibited a statistically significant intracellular oxidant increase as compared to the control cells. These physicochemical characterization results suggest that the lab formulated paint products are a suitable surrogate of typical nano-enabled consumer products that could be used as a standard material for bridging studies, predictive studies, and simulated studies.

In conclusion, electron microscopy and elemental analysis as analytical chemistry characterization tools were able to detect the 
Citation: Sayes CM, Sooresh A, Meissner KE (2015) Physicochemical Characteristics of Two Prototypical Home-Use Consumer Products Containing Engineered Nanomaterials. J Environ Anal Toxicol 5: 326. doi:10.4172/2161-0525.1000326

A

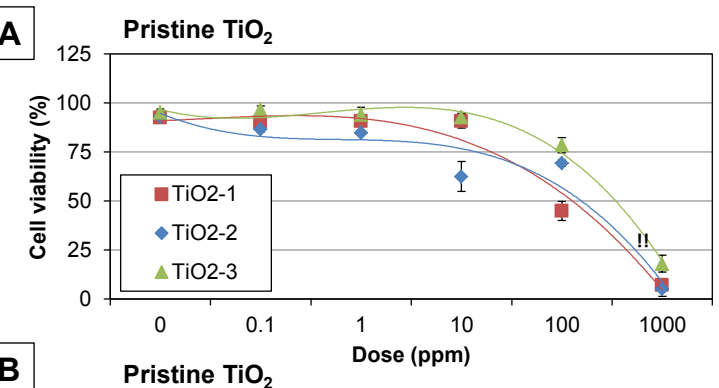

B

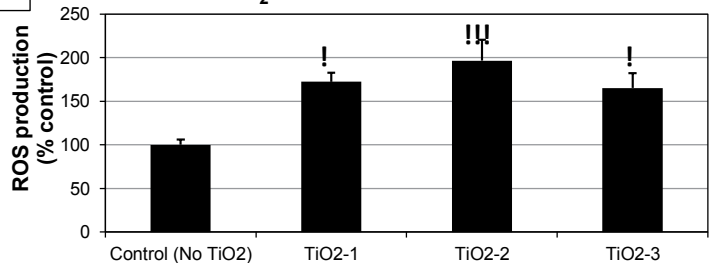

C

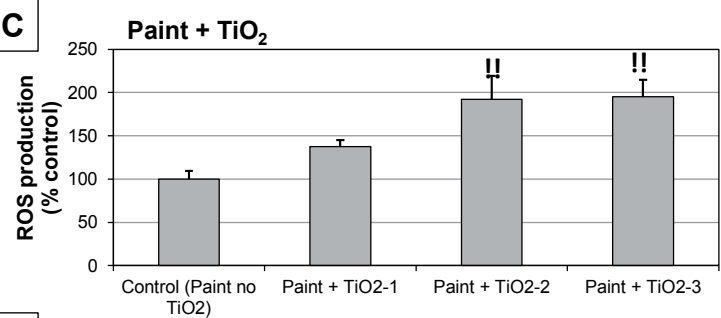

D

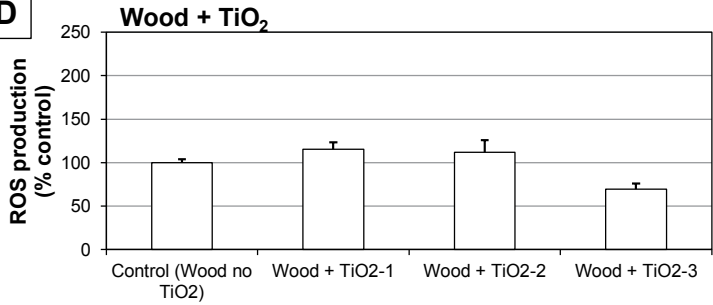

Figure 5: Cellular assessments. (A) Cell viability of pristine $\mathrm{TiO}_{2}$ nanoparticles as measured using trypan blue exclusion assay, (B) ROS generation after exposure to $100 \mathrm{ppm}$ of pristine $\mathrm{TiO}_{2}$ nanoparticles, (C) ROS generation after exposure to $100 \mathrm{ppm}$ of powders collected after wear-and-tear of paint on drywall and (D) ROS generation after exposure to $100 \mathrm{ppm}$ of powders collected after wear-and-tear of lacquered wood. Data were normalized to the control values (i.e. measured data divided by control measure for that same time point or concentration) and are represented as the mean \pm SEM (*: $\mathrm{P}<0.05$; **: $\mathrm{P}<0.01$; ***: $\mathrm{P}<0.001)$.

nanoparticles in the worn-and- torn complex paint and lacquer matrices. FTIR, on the other hand, proved to be a useful tool for the nano-enabled paint samples, but the nano-enabled lacquered wood samples warrant further investigation. These results validate the usefulness of TEM, SEM and EDX as part of a suite of predictive tools ready to analyze nano-enabled products. FTIR as a material characterization technique, however, is only valid when relatively high concentrations (greater than $15 \% \mathrm{w} / \mathrm{w}$ ) of the nanoparticles are incorporated into the products. Furthermore, in vitro ROS generation of both of pristine and worn-and-torn powders provides a more realistic platform for data interpretation and the identification of risk triggers. Thus, the application of a product life cycle approach will help provide critical information to evaluate potential health and environmental risks and benefits of a nano-scale technology.

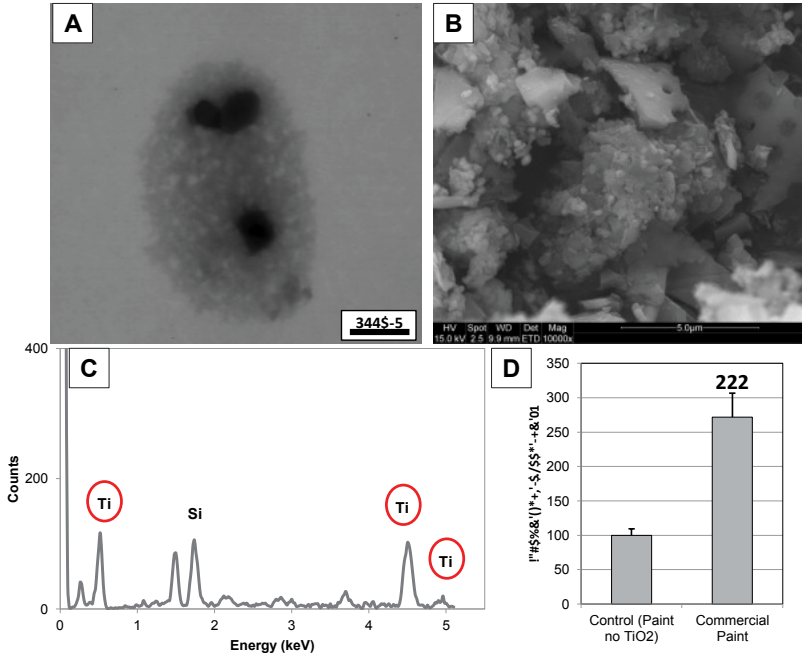

Figure 6: Material Characterization and ROS generation of particles collected after wear-and-tear of commercial paint on drywall. (A) TEM, (B) SEM, (C) SEM-EDX spectra and (D) ROS generation after exposure to 100 ppm worn-and-torn commercial paint particles.

\section{Acknowledgements}

This research was funded through an internal research and development grant at RTI International. Texas A \& M University is also acknowledged for their support of this work.

\section{References}

1. Oberdörster G, Oberdörster E, Oberdörster J (2005) Nanotoxicology: an emerging discipline evolving from studies of ultrafine particles. Environ Health Perspect 113: 823-839.

2. Oberdörster G, Maynard A, Donaldson K, Castranova V, Fitzpatrick J, et al. (2005) Principles for characterizing the potential human health effects from exposure to nanomaterials: Elements of a screening strategy. Part Fibre Toxicol 2: 8 .

3. Sepeur, European Coatings Tech Files. Nanotoxicology: Technical Basics and Applications Hannover: Vincentz Network 2008.

4. Hansen SF, Larsen BH, Olsen SI, Baun A (2007) Categorization framework to aid hazard identification of nanomaterials. Nanotoxicology 1: 243-250.

5. SCENIHR (2006) The appropriateness of existing methodologies to assess the potential risks associated with engineered and adventitious products of nanotechnologies.

6. Sondi I, Salopek-Sondi B (2004) Silver nanoparticles as antimicrobial agent: a case study on E. coli as a model for Gram-negative bacteria. J Colloid Interface Sci 275: 177-182.

7. Saber AT, Jensen KA, Jacobsen NR, Birkedal R, Mikkelsen L, et al. (2012) Inflammatory and genotoxic effects of nanoparticles designed for inclusion in paints and lacquers. Nanotoxicology 6: 453-471.

8. Baan RA (2007) Carcinogenic hazards from inhaled carbon black, titanium dioxide, and talc not containing asbestos or asbestiform fibers: Recent evaluations by an IARC Monographs Working Group. Inhal Toxicol 19: 213228.

9. Baan RA (2010) IARC monographs on the evaluation of carcinogenic risks to humans. 93: 9-38.

10. Saber AT, Jacobsen NR, Mortensen A, Szarek J, Jackson P, et al. (2012) Nanotitanium dioxide toxicity in mouse lung is reduced in sanding dust from paint. Part Fibre Toxicol 9: 4

11. Roco MC, Mirkin CA, Hersam MC (2011) Nanotechnology research directions for societal needs in 2020: Summary of international study. Journal of Nanoparticle Research 13: 897-919. 
Citation: Sayes CM, Sooresh A, Meissner KE (2015) Physicochemical Characteristics of Two Prototypical Home-Use Consumer Products Containing Engineered Nanomaterials. J Environ Anal Toxicol 5: 326. doi:10.4172/2161-0525.1000326

12. Nazarenko Y, Han TW, Lioy PJ, Mainelis G (2011) Potential for exposure to engineered nanoparticles from nanotechnology-based consumer spray products. J Expo Sci Environ Epidemiol 21: 515-528.

13. Lee J, Mahendra S, Alvarez PJ (2010) Nanomaterials in the construction industry: a review of their applications and environmental health and safety considerations. ACS Nano 4: 3580-3590.

14. Lee J, Mahendra S, Alvarez PJJ (2009) Potential Environmental and Human Health Impacts of Nanomaterials Used in the Construction Industry. Nanotechnology in Construction 3: 1-14.

15. Warheit DB, Webb TR, Reed KL, Frerichs S, Sayes CM (2007) Pulmonary toxicity study in rats with three forms of ultrafine- $\mathrm{TiO}_{2}$ particles: Differential responses related to surface properties. Toxicology 230: 90104.

16. Comprehensive Environmental Assessment Applied to: Multi-walled Carbon Nanotube Flame Retardant Coatings in Upholstery Textiles- A Case Study Presenting Priority Research Gaps for Future Risk Assessments ER.

17. Mueller NC, Nowack B (2008) Exposure modeling of engineered nanoparticles in the environment. Environ Sci Technol 42: 4447-4453.

18. Gottschalk F, Nowack B (2011) The release of engineered nanomaterials to the environment. J Environ Monit 13: 1145-1155.

19. Abbott LC, Maynard AD (2010) Exposure assessment approaches for engineered nanomaterials. Risk Anal 30: 1634-1644.

20. Grieger KD, Laurent A, Miseljic M, Christensen F, Baun A, et al. (2012) Analysis of current research addressing complementary use of life-?cycle assessment and risk assessment for engineered nanomaterials: Have lessons been learned from previous experience with chemicals. Journal of Nanoparticle Research 14: 958.

21. Shi H, Magaye R, Castranova V, Zhao J (2013) Titanium dioxide nanoparticles: a review of current toxicological data. Part Fibre Toxicol 10: 15

22. Lyon DY, Fortner JD, Sayes CM, Colvin VL, Hughe JB (2005) Bacterial cell association and antimicrobial activity of a $\mathrm{C} 60$ water suspension. Environ Toxicol Chem 24: 2757-2762.

23. Polymers CE (2012) EcoVAE® Interior Quality Fla; www.celanese-emulsions. com

24. Allen NS, Edge M, Verran J, Caballero L, Abrusci C, et al. (2010) Photocatalytic Surfaces: Antipollution and Antimicrobial Effects. Nanotechnology 2: 17-50.

25. Ozgenc O, Hiziroglu S, Yildiz UC (2012) Weathering properties of wood species treated with different coating applications. BioResources 7: 4875-4888.

26. Vlad-Cristea M, Riedl B, Blanchet P, Jimenez-Pique E (2012) Nanocharacterization techniques for investigating the durability of wood coatings. European Polymer Journal 48: 441-453.

27. Vorbau M, Hillemann L, Stintz M (2009) Method for the characterization of the abrasion induced nanoparticle release into air from surface coatings. Journal of Aerosol Science 40: 209-217.
28. Göhler D, Stintz M, Hillemann L, Vorbau M (2010) Characterization of nanoparticle release from surface coatings by the simulation of a sanding process. Ann Occup Hyg 54: 615-624.

29. Carp O (2004) Photoinduced reactivity of titanium dioxide. Progress in Solid State Chemistry 32: 33-177.

30. Chen X, Mao SS (2007) Titanium dioxide nanomaterials: synthesis, properties, modifications, and applications. Chem Rev 107: 2891-2959.

31. Mills A, Davies RH, Worsley D (1993) Water-purification by semiconductor photocatalysis. Chemical Society Reviews 22: 417-425.

32. Allen NS, Edge M, Ortega A, Sandoval G, Liauw CM, et al. (2004) Degradation and stabilisation of polymers and coatings: Nano versus pigmentary titania particles. Polymer Degradation and Stability 85: 927-946

33. Allen NS, McKellar JF (1980) Photochemistry of dyed and pigmented polymers

34. Allen NS, Katami H (1996) Comparison of various thermal and photoageing conditions on the oxidation of titanium dioxide pigmented linear low density polyethylene films. Polymer Degradation and Stability 52: 311-320.

35. Allen NS, Edge M, Ortega A, Liauw CM, Stratton J, et al. (2002) Behaviour of nanoparticle (ultrafine) titanium dioxide pigments and stabilisers on the photooxidative stability of water based acrylic and isocyanate based acrylic coatings. Polymer Degradation and Stability 78: 467-478.

36. Beattie IR, Gilson TR (1969) Oxide phonon spectra. Journal of the Chemical Society A: Inorganic, Physical, Theoretical 0: 2322-2327.

37. López T, Moreno JA, Gómez R, Bokhimi X, et al. (2002) Characterization of iron-doped titania sol-gel materials. Journal of Materials Chemistry 12: 714718.

38. Luo HL, Sheng J, Wan YZ (2008) Preparation and characterization of $\mathrm{TiO}_{2} /$ polystyrene core-shell nanospheres via microwave-assisted emulsion polymerization. Materials Letters 62: 37-40.

39. Mohamed MM, Bayoumy WA, Khairy M, Mousa MA (2006) Synthesis and structural characterization of $\mathrm{TiO}_{2}$ and $\mathrm{V}_{2} \mathrm{O}_{5} / \mathrm{TiO}_{2}$ nanoparticles assembled by the anionic surfactant sodium dodecyl sulfate. Microporous and Mesoporous Materials 97: 66-77.

40. Wang J, Li RH, Zhang ZH, Sun W, Wang XF, et al. (2008) Heat treatment of nanometer anatase powder and its photocatalytic activity for degradation of acid red B dye under visible light irradiation. Inorganic Materials 44: 608-614.

41. Erdem B, Hunsicker RA, Simmons GW, David Sudol E, Dimonie VL, et al. (2001) XPS and FTIR surface characterization of $\mathrm{TiO}_{2}$ particles used in polymer encapsulation. Langmuir 17: 2664-2669.

42. Borm PJ, Robbins D, Haubold S, Kuhlbusch T, Fissan H, et al. (2006) The potential risks of nanomaterials: a review carried out for ECETOC. Part Fibre Toxicol 3: 11.

43. Hospenthal DR, Murray CK, Andersen RC, Bell RB, Calhoun JH, et al. (2011) Guidelines for the prevention of infections associated with combat-?related injuries: 2011 update: endorsed by the Infectious Diseases Society of America and the Surgical Infection Society. J Trauma 71: S210-34. 